\title{
WHEN IS A SPECIES EXTINCT? QUANTITATIVE INFERENCE OF THREAT AND EXTINCTION FROM HERBARIUM DATA
}

\author{
DAVID L. RoBerts ${ }^{1} \&$ GREG J. MCINERNY ${ }^{2}$ \\ ${ }^{1}$ Royal Botanic Gardens, Kew, Richmond, Surrey TW9 3AB, U.K. (E-mail d.roberts@rbgkew.org.uk) \\ ${ }^{2}$ School of Biological Sciences, University of East Anglia, Norwich, Norfolk, NR4 7TJ, U.K.
}

We are now entering a time of immense environmental upheaval were, increasingly, experts are required to provide conservation assessments. Quantitative assessment of trends in range and abundance is costly, requiring extensive field studies over a long period of time (Burgman et al. 2000). Unfortunately, many species are only known through a few 'chance' sightings or a handful of specimens and extinction may be even harder to ascertain (Solow \& Roberts, in press).

Organisations such as CITES and the World Conservation Union have considered a species to be extinct when it has not been observed for 50 years (Reed 1996). As a criterion, its usefulness was dependent on the characteristics of the species in question. For example, not observing a species of insect, with a short generation time, would clearly not be comparable with not seeing a turtle for 50 years, which spends extended periods at sea. Revision of the categories resulted in species being classified 'extinct' when exhaustive surveys failed to produce any observations over a time period appropriate to the species' life history and throughout its known historical range (IUCN 2001).

Quantitative inference of threat and extinction. Using a record of sightings, Solow (1993a, 1993b) demonstrated two methods to test the hypothesis of extinction on the basis of the period without sighting and the previous sighting record. The indices produce probabilistic inference of extinction in the absence of biological information (Solow \& Helser 2000), as little is known of so many species, and extinctions are rarely observed directly (Solow \& Helser 2000, Solow \& Roberts, in press). Similar methods have been presented which also look at the behaviour of the most recent sightings in the record (Solow \& Roberts, in press) and can reduce the effect of periods where little collection effort has occurred (McCarthy 1998). Examination of these indices has been carried out with sighting data recorded for species of varying taxa (see Burgman 1995, McCarthy 1998, Burgman et al. 2000, Roberts \& Wilcock, in press). Evaluation against recognised conservation classifications suggested that the indices can infer threat and aid in the prioritisation of species for conservation attention (McCarthy 1998). Specimen-based records provide information on the distribution of taxa through time and space (Ponder et al. 2001), of which there is a wealth held in the taxonomic collections and libraries of herbaria and museums. Methods such as these potentially have wide application as indicators of threat.

Lists of threatened species often form the primary source of information in the allocation of limited resources (Burgman 2002). Here we present a number of quantitative methods for rapidly assessing threat and extinction based on herbarium data.

Solow Equation. Using the time of the last sighting $\left(t_{n}\right)$ the Solow equation gives the probability that $n$ observations occurred within the period $0 \leq t \leq t_{\mathrm{n}}$, given that sightings are equally likely to occur within the period $T$ (Solow 1993a) (Fig. 1). Therefore higher probability values $(>\alpha)$ infer that extinction has not occurred as the lack of sightings at the end of the record could happen by chance. Low probabilities $(<\alpha)$ infer that extinction has occurred as the sightings are unlikely to have occurred in the time period 0 $\leq t \leq t_{n}$ given the magnitude of $T$ and/or $n$.

$$
p-\left(\begin{array}{c}
l_{n} \\
T
\end{array}\right)^{n}
$$


Solow Equation for a declining population. The Solow equation (1993a) is suitable for small populations that are predisposed to rapid extinction, as the sightings are assumed to follow a stationary Poisson process (Solow 1993b). However, in a declining population sightings are less likely to occur towards the end of the period because sightings will reduce as the population declines. Assuming that the sightings follow a Poisson process with decreasing rate function Solow developed the following equation (Solow 1993b).

$$
p=F s\left(t_{n}\right) / F s(T)
$$

where

$$
s=\sum_{i=1}^{n} t i
$$

and the function $F s(t)$ is given by

$$
F_{s}(t)=1-\sum_{i=1}^{[s / t]}(-1)^{i-1}\left(\begin{array}{c}
n \\
i
\end{array}\right)(1-(i t / s))^{n-1}
$$

Solow / Roberts Equation.The Solow/Roberts nonparametric test (Solow \& Roberts, in press) does not require a complete sighting record, as the number of sightings $(n)$ is not required for its calculation (Solow $\&$ Roberts, in press). Using $t_{n}, T$ and $t_{n-1}$ (the second to last sighting) the equation generates the probability that another sighting will occur (Fig. 2). However, the equation for a declining population does not make any assumption that the sightings follow a Poisson process.

$$
p=\left(\frac{t_{n}-t_{n-1}}{T-t_{n-1}}\right)
$$

Collection effort. Collection effort is clearly not a uniform process and therefore it is important to eliminate inaccuracies arising from trends in collection effort through herbarium practices and access to sites (i.e. wars, CITES and government permits, funding, remote location, etc). Instead of using time as a measure of the period between sightings collec-

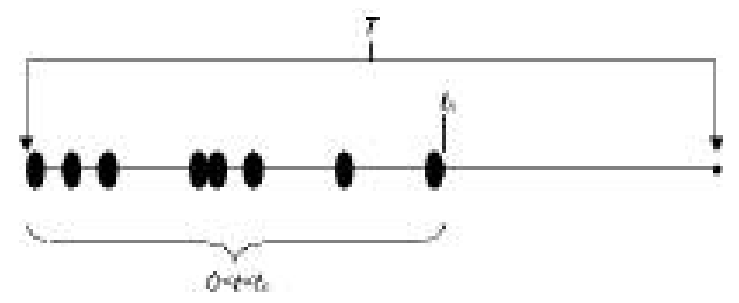

Fig. 1. The Solow equation evaluates the probability that $\mathrm{n}$ observations occurred before the last sighting during the period $T$.

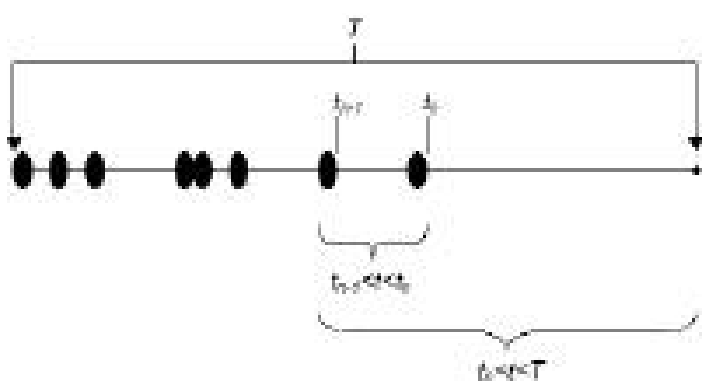

Fig. 2. The probability of another sighting occurring is generated based on the ratio between the periods $t_{n-1}<t<t_{n}$ and $t_{n-1}<t<T$.

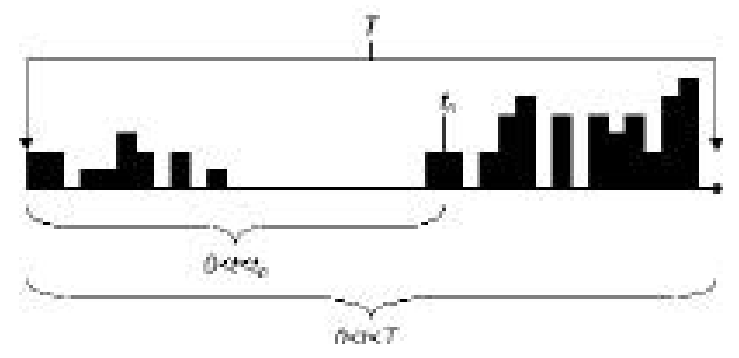

Fig. 3. The Partial Solow equation generates probabilities based on the collection effort producing $\mathrm{n}$ sightings given the total effort within the whole period.

tion effort can be used (Fig. 3). McCarthy (1998) modified the Solow equation to incorporate an index of collection effort for each year (ei) (Partial Solow equation). Collection effort can be calculated as the proportion of the total species observed in each time unit (McCarthy, pers. comm. 2002), assuming all species have an equal chance of being observed at any time in the locality. If collection effort does not vary over the period ( 0 to $\mathrm{T}$ ), then the equation reduces to the Solow equation (McCarthy, 1998). 


\section{Partial Solow Equation.}

$$
p=\left(\frac{\sum_{i=1}^{t_{n}} e_{i}}{\sum_{i=1}^{T} e_{i}}\right)^{n}
$$

This method can also be applied to the Solow / Roberts equation.

Start Dates. In the case of say annual bird counts, it is possible to select a start date for the period $T$, however in many cases this is rarely possible. By using the first sighting as the start date the number of sightings, $n$, reduces to $n-1$, limiting the number of species with calculable probabilities.

Inferring decline. Increasing magnitude of $p$-values implies decreasing levels of threat (McCarthy 1998). If species were collected randomly and were not in decline, then one would expect that the distribution would be uniform, for example species that are presumed extinct would have the lowest $p$ values (McCarthy 1998). If 50 species were examined, by chance we would expect 5 species to have $p$-values below $0.1,10$ species below 0.2 and so on.

Testing the tests. Error rates can be calculated as the actual proportion of extant species inferred as extinct $(p<\alpha)$ for all sighting records and indices (McCarthy 1998).

Power of the indices is calculated as the proportion of species correctly identified as extinct (McCarthy 1998).

IUCN categories of threat, where available, can be used as a source of information for the 'true' status of a species by which the equations can be evaluated using the Spearman's rank correlation (McCarthy 1998).

An illustrated example. The record of Aeranthes arachnites (Thou.) Lindl. from Mauritius, Indian Ocean, contains $n=5$ collections during the 20th century 1960, 1962, 1964, 1968 and 1973. If the beginning of the observation period is taken to be the time of the first collection in 1960, $n$ is reduced by 1 , and $T=40$ (i.e. from 1960 to 2000 ), the $p$ value based on the assumption of a constant collecting rate is 0.012 . The smallness of this $p$-value is due to the apparent decline in the collecting rate over the observation period. If, instead, we assume that the collecting rate declines exponentially, then the $p$-value is 0.306 , reflecting the expected increasing difficulty in locating the species. While the collection record gives some evidence of such a decline, it is not possible to determine from so small a record whether the exponential model is reasonable. However, if we make no assumption of the rate of decline then $p=0.15625$. This would therefore suggest that the species is still present on Mauritius. Based on 16 months of field work in Mauritius, this species still exists.

\section{LiTERATURE Cited}

Burgman, M.A., R.C. Grimson and S. Ferson. 1995. Inferring threat from scientific collections. Conserv. Biol. 9: 923-928.

Burgman, M.A. 2002. Turner Review No. 5: Are listed threatened plant species actually at risk? Austral. J. Bot. 50: 1-13.

Burgman, M.A., B.R. Maslin, D. Andrewartha, M.R. Keatley, C. Boek and M. McCarthy. 2000. Inferring threat from scientific collections: power tests and an application to Western Australian Acacia species. In S. Ferson and M.A. Burgman (eds.), Quantitative Methods for Conservation Biology. Springer-Verlag New York, Inc. p. 7-26.

IUCN 2001. IUCN Red List Categories: Version 3.1. Prepared by the IUCN Species Survival Commission. IUCN, Gland, Switzerland and Cambridge, UK.

McCarthy, M.A. 1998. Identifying declining and threatened species with museum data. Biol. Conserv. 83: 9-17.

Ponder, W.F., G.A. Carter, P. Flemons and R.R. Chapman. 2001. Evaluation of museum collection data for use in biodiversity assessment. Conserv. Biol. 15: 648-657.

Reed, J.M. 1996. Using statistical probability to increase confidence of inferring species extinction. Conserv. Biol. 10: 1283-1285.

Roberts, D.L. and C.C. Wilcock. in press. Fragmentation of tropical rainforests and its effect on orchid survival. Proceedings of the 17th World Orchid Conference.

Solow, A.R. 1993a. Inferring extinction from sighting data. Ecology 74: 962-964.

Solow, A.R. 1993b. Inferring extinction in a declining population. J. Mathem. Biol. 32: 79-82. 
Solow, A.R. and T. Helser. 2000. Detecting extinction in sighting data. In S. Ferson and M.A. Burgman (eds.), Quantitative Methods for Conservation Biology.
Springer-Verlag New York, Inc. p. 1-6.

Solow, A. and D.L. Roberts. in press. A nonparametric test for extinction based on a sighting record. Ecology.

David Roberts was educated at the Universities of Aberystwyth, Wales and Aberdeen, Scotland, where he received his doctoral on the "Reproductive Biology and Conservation of the Orchids of Mauritius". He has had field experience in Mauritius, La Reunion, Rodrigues, Borneo, and the Chatham Islands. Currently David is an orchid taxonomist at the Royal Botanic Gardens, Kew, where he has a particular interest in the orchids of tropical Africa, islands of the western Indian Ocean and alterative uses of herbarium data particularly relating to conservation biology. 